\title{
Use of commercial infant cereals as complementary food in infants and young children in Ghana
}

\author{
Abdul-Razak Abizari*, Zakari Ali, Collins Nana Essah, Patience Agyeiwaa and Margaret Amaniampong
}

\begin{abstract}
Background: Typical complementary foods in developing countries are often inadequate in multiple micronutrients. One way of preventing micronutrient deficiency among infants and young children (IYC) is to feed them a variety of nutrient dense foods. The use of commercial infant cereals (CIC) as complementary food is increasing in Ghana. However, it is unknown whether giving $\mathrm{CIC}$ may discourage inclusion of other locally available and nutritious foods as mothers may hold the notion that $\mathrm{ClC}$ is superior. This study therefore examined the use of $\mathrm{ClC}$ as complementary food, the micronutrient intake from $\mathrm{CIC}$ and reasons for its use.
\end{abstract}

Methods: A cross-sectional study was conducted involving mothers with IYC aged 6-23 months who give CIC as complementary food. Questionnaires were administered to estimate the usual daily frequencies and quantities of CIC. Micronutrient intakes from $\mathrm{ClC}$ were calculated. We also calculated the proportion of the recommended nutrient intake (RNI) contributed by micronutrients from CIC.

Results: Of the 384 children sampled, $64.6 \%$ were aged $13-23$ months and $50.3 \%$ were females. More than half of the mothers earned income through trading (55.2\%) and nearly one quarter of them had senior high school education (24. 7\%). Majority of the children consumed 3-4 tablespoons (52.3\%) of CIC in a feeding moment. Younger children (612 months) were served $\mathrm{ClC}$ more frequent than older children (13-23 months). The mean \pm SD of micronutrients from ClC were $6.76 \pm 2.67 \mathrm{mg}, 4.79 \pm 1.70 \mathrm{mg}, 384.12 \pm 139.69 \mathrm{mg}, 266.70 \pm 100.74 \mathrm{mg}$ and $69.11 \pm 24.65 \mu \mathrm{g}$ for the minerals Fe, Zn, Ca, P and I respectively. The vitamin intakes were: $337.17 \pm 119.70 \mu \mathrm{g}, 42.88 \pm 15.28 \mathrm{mg}, 0.84 \pm 0.31 \mu \mathrm{g}$, $34.24 \pm 12.22 \mu \mathrm{g}$ and $2.70 \pm 1.03 \mathrm{mg}$ for vitamin A, vitamin C, vitamin B12, folic acid and niacin respectively.

Micronutrients from $\mathrm{CIC}$ consumption contributed to at least $70 \%$ of the RNIs for $\mathrm{Fe}, \mathrm{Zn}$, Ca, l, vitamin A, vitamin C and vitamin B12. Mothers believed that CIC alone could meet the nutritional needs of children and ensure optimal growth and health.

Conclusion: The results of present study show that use of $\mathrm{CIC}$ as complementary food was high among mothers with IYC 6-12 months. Mothers believed that CIC was nutritionally adequate for their children and did not see the need to include or enrich other locally available complementary foods. Mothers should be educated on the need to include other foods with $\mathrm{CIC}$ to increase the dietary quality of IYC.

Keywords: Commercial infant cereals, Micronutrients, Young children, Ghana

\footnotetext{
* Correspondence: abizaria@yahoo.com

Department of Nutritional Sciences, School of Allied Health Sciences,

University for Development Studies, P.O. Box TL 1883, Tamale, Ghana
} 


\section{Background}

Adequate nutrition during infancy and early childhood is fundamental to the development of a child's full potential [1]. Micronutrient deficiency is of public health concern in developing and developed countries and affects about 2 billion people [2]. Given the increased nutrient demands of young children, they are one of the population groups most vulnerable to micronutrient deficiencies [3]. Childhood deficiency in zinc and vitamin A is linked to child deaths [4]. The combined effect of iodine deficiency and stunted growth also affect a child's development potential [4].

Breast milk alone can totally satisfy the nutritional requirements of infants within the first 6 months after birth [5]. After this period, breast milk becomes inadequate for optimal growth and development and complementary foods are introduced to increase energy and nutrient intake [6]. Breastfeeding is recommended to continue along with complementary feeding until a child's second birthday or beyond [6]. Complementary feeding is important, considering the rapid mental and physical developments that take place in this age group which occur with a particularly high need for micronutrient intake [7]. Foods for complementary feeding therefore need to be more nutrient-rich than the foods typically consumed by other age groups in the household [8]. Complementary foods are regarded transitional foods and usually include local and industrially processed foods [9] including CIC [10].

Typical complementary foods in developing countries are often inadequate in multiple micronutrients especially iron and zinc $[8,11,12]$. To ensure adequate nutrition in these children, the World Health Organization recommends age appropriate complementary feeding that meets both frequency and diversity $[6,13]$. It is recommended that IYC consume from at least four out of seven core food groups in a day to ensure adequate nutrient intake [13]. Dietary diversity is shown to be associated with adequate micronutrient intake in different developing country settings $[14,15]$. Even though CIC are fortified with some micronutrients [16], mostly iron [17], calcium, zinc, phosphorus, thiamine, riboflavin and niacin [18] which are key to the growth and development of IYC, consumption these foods alone may not meet daily recommended needs of IYC [19].

$\mathrm{CICs}$ are increasingly becoming popular as complementary food in Ghana, especially among urban mothers $[20,21]$. As mothers may hold the notion that $\mathrm{CIC}$ are superior to local complementary foods, CIC use may discourage inclusion of other locally available and nutritious foods and reducing dietary diversity of IYC. CIC usage and consumption levels among IYC, the reasons mothers may prefer feeding their IYC with CIC instead of using locally available, nutritious and relatively cheap alternatives are unknown. This study therefore examined the use of CIC as complementary food, the consumption levels among IYC, the micronutrient content of commonly used $\mathrm{CIC}$ and reasons mothers may prefer CIC to enriching local complementary foods.

\section{Methods}

\section{Study area}

This study was conducted in Tamale, the administrative capital of the Northern region of Ghana. Tamale is one of the largest cities in Ghana and a metropolitan with an estimated land size of $646.9 \mathrm{sq} . \mathrm{km}$ located in the central part of the Region [22]. The total population size of the metropolis is estimated at 233,252 which is about $9.4 \%$ of the region's population. The population is largely urban $(80.8 \%)$ with a few living in rural localities (19.1\%) of the metropolis. Women of reproductive age (1549 years) in the metropolis make up about $23.8 \%$ of the population and children aged $0-4$ years are $14 \%$ of the total population. The General Fertility Rate is 79.9 births per 1000 women aged 15-49 years. There are four major markets in the Metropolis namely: Central Market, Aboabo, Kukuo and Lamashegu. In addition to these, there are satellite markets in large suburbs of the Metropolis. The Central market comprises of mini shops and stalls. There are also supermarkets in the city where commercial infant cereals are purchased [23].

\section{Design, target population and sampling}

A descriptive cross sectional study design was used in the present study. The target population was mothers with infants and young children 6-23 months in Tamale Metropolis. This study included only mothers who had children 6-23 months and used commercial infant cereal as part of complementary foods given to the child.

Using an alpha of 1.96 at $95 \%$ confidence interval with a permitted 5\% margin of error and an assumed 50\% prevalence of micronutrient adequacy from commercial infant cereals in the Northern region, the required sample size was 384. Data were collected mainly from five urban suburbs (Aboabo, Lamashegu, Vitting, Sakasaka, and Nyohini) within the Tamale metropolis through visits to selected households. Mothers using $\mathrm{CIC}$ as complementary food in selected communities were first identified at child welfare clinics and followed home to complete informed consent and research questionnaire. Recruitment at child welfare clinics continued until the required sample size was met.

\section{Data collection tools and procedures}

Semi structured questionnaires were used for data collection. Questionnaire administration was done through face-to-face interviews in the language the respondent understood. The questionnaire elicited information 
about maternal and child demographic characteristics, use of commercial infant cereal, preferred brand of infant cereal, number of times $\mathrm{CIC}$ is served in a day, and quantity of CIC fed to child in a feeding moment.

Estimation of quantity of infant cereal consumed in a day The number of times $\mathrm{CIC}$ was consumed during the preceding $24 \mathrm{~h}$ and the estimated number of tablespoons of CIC consumed by children per feeding moment were determined by recall. For mothers who gave sachets $(50 \mathrm{~g})$ of $\mathrm{CIC}$, their equivalents in household tablespoons were estimated. The total tablespoons of CIC consumed in a day by children was calculated by multiplying the number of times CIC was consumed in a day by the average (usual) number of tablespoons of $\mathrm{CIC}$ consumed per feeding moment.

From a subgroup of 20 mothers, we estimated the quantity (in grams) of CIC equivalent to a typical tablespoon given by mothers. We used the two most preferred brands of CIC (Cerelac and Yumvita) for this estimation. Mothers were presented their preferred brand and asked to use their usual household tablespoon to fetch a usual tablespoonful of CIC for their infant or young child. Each mother or caregiver gave two scoops of a usual tablespoonful of CIC. Each scoop was weighed with an electronic scale (Citizen $\mathrm{CY} 360$, precise to $20 \mathrm{mg}$ ) and an average of the two was taken as the estimated weight of the usual tablespoonful for each brand of CIC. The average weight of a typical tablespoonful of CIC offered to children was calculated from the averages of the two most preferred brands.

\section{Estimation of daily micronutrient intake from $\mathrm{CIC}$}

Daily micronutrient intake of children from CIC was estimated by determining the micronutrient content of a typical tablespoon of the preferred brand of CIC and the total tablespoons consumed in a day. The micronutrient content of the preferred brand and flavour of CIC was listed per $100 \mathrm{~g}$ of the product by the manufacturer. The micronutrient content of a typical tablespoon of mother's preferred brand and flavour of CIC was calculated by proportion. Vitamin A content of CIC was stated in international units (IU), these were converted to micrograms $(\mu \mathrm{g})$ by multiplying by 0.3 [24]. The amount of micronutrients consumed in a day by IYC from CIC was calculated by multiplying the amount of micronutrient in a typical tablespoon of the preferred brand and flavour by the total tablespoons of CIC consumed in a day. We made the following assumptions for the estimation of daily micronutrient intake from CIC: (i) children completely consumed the quantity of CIC prepared for them per eating moment (ii) the micronutrient content of different brands (as listed by the CIC manufacturers) are reasonably stable. Probabilities of inadequacy of the micronutrients were not calculated as at least two days of repeated dietary recalls are required [24]. We calculated the proportion of the RNI contributed by micronutrients from CIC. We used RNIs provided by $\mathrm{FAO} / \mathrm{WHO}$ [25] and assumed $12 \%$ and moderate bioavailability for iron and zinc respectively.

\section{Data analysis}

Data was entered, cleaned and analyzed using IBM SPSS (version 21). Continuous data were presented as means and standard deviations while categorical data were presented as frequencies and percentages.

\section{Results}

Socio-demographic characteristics of respondents

The mean \pm SD age of mothers in this study was $28.7 \pm 4.7$ years and four in ten mothers were within the age range 25-29 years (40.1\%). Two-thirds of the mothers/caregivers have attained at least junior high school education. Majority of the mothers were married (92.2\%), practiced Islamic religion (75.3\%), earned income through trading (55.2\%) and were from the Dagomba ethnic group (58.1\%). The average child in this study was a little above the first birthday (14.9 \pm 4.8 months) with more than six in ten aged 1323 months $(64.6 \%)$. The proportion of female children in the sample was a little more than half (50.3\%) (Table 1).

\section{Knowledge and opinion of respondents on commercial infant cereal utilization}

Table 2 presents information on the knowledge and opinions of mothers on the use of CIC. The majority of the mothers had information about CIC from the media (radio and television advertisements) (50.3\%) and knew at least two brands (57.0\%) of CIC on the Ghanaian market. Although the majority of mothers knew more than one brand of CIC, more than nine in ten mothers purchased Cerelac brand (Nestle). Majority of mothers purchased CIC packaged in tin containers (79.9\%) rather than single use packs. Forty-six percent of mothers held more than one reason for using $\mathrm{CIC}$ as complementary food for their children. Some of the specific reasons given for utilization of CIC include: CIC help in infant growth and development (29.7\%), it provides sufficient nutrients for infants and young children (9.4\%) and easy to prepare (4.2\%).

\section{Daily intake of commercial infant cereal by infants and young children}

Children ate between 1 and 5 tablespoons of CIC in a feeding moment. Overall, most of them ate 3-4 tablespoons $(52.3 \%)$ of CIC in a feeding moment. The number of tablespoons of $\mathrm{CIC}$ consumed by children in a serving differed by age group. For instance, while the 
Table 1 Demographic characteristics of sample

\begin{tabular}{|c|c|c|c|}
\hline Characteristics & Mean \pm SD & Frequency & Percentage \\
\hline \multicolumn{4}{|l|}{ Child characteristics } \\
\hline \multicolumn{4}{|l|}{ Sex } \\
\hline Male & & 191 & 49.7 \\
\hline Female & & 193 & 50.3 \\
\hline Mean age (months) & $14.9 \pm 4.8$ & & \\
\hline \multicolumn{4}{|l|}{ Age group (months) } \\
\hline $6-12$ & & 136 & 35.4 \\
\hline $13-23$ & & 248 & 64.6 \\
\hline \multicolumn{4}{|l|}{ Maternal characteristics } \\
\hline Mean age of mothers (years) & $28.7 \pm 4.7$ & & \\
\hline \multicolumn{4}{|l|}{ Age group of mothers (years) } \\
\hline$<20$ & & 2 & 0.5 \\
\hline $20-24$ & & 65 & 16.9 \\
\hline $25-29$ & & 154 & 40.1 \\
\hline $30-34$ & & 118 & 30.7 \\
\hline $35-39$ & & 35 & 9.1 \\
\hline $40+$ & & 10 & 2.6 \\
\hline \multicolumn{4}{|l|}{ Education } \\
\hline None & & 77 & 20.1 \\
\hline Primary & & 50 & 13.0 \\
\hline JHS & & 90 & 23.4 \\
\hline SHS & & 95 & 24.7 \\
\hline Tertiary & & 72 & 18.8 \\
\hline \multicolumn{4}{|l|}{ Marital status } \\
\hline Married & & 354 & 92.2 \\
\hline Currently unmarried & & 4 & 1.0 \\
\hline \multicolumn{4}{|l|}{ Religion } \\
\hline Islam & & 289 & 75.3 \\
\hline Christian & & 93 & 24.2 \\
\hline Other & & 2 & 0.5 \\
\hline \multicolumn{4}{|l|}{ Ethnicity } \\
\hline Dagomba & & 223 & 58.1 \\
\hline Gonja & & 51 & 13.3 \\
\hline Akan & & 50 & 13.0 \\
\hline Other & & 60 & 15.6 \\
\hline \multicolumn{4}{|l|}{ Occupation } \\
\hline Farmer & & 14 & 3.6 \\
\hline Trader & & 212 & 55.2 \\
\hline Civil servant & & 69 & 18.0 \\
\hline Unemployed & & 38 & 9.9 \\
\hline Other & & 51 & 13.3 \\
\hline
\end{tabular}

majority of children aged 6-12 months ate at least 2 tablespoons (80.9\%), the majority of those aged 1323 months ate 3-4 tablespoons (70.6\%) in a feeding
Table 2 Knowledge on commercial infant cereal and maternal opinions on its use

\begin{tabular}{|c|c|c|}
\hline Item & Frequency & Percentage \\
\hline \multicolumn{3}{|l|}{ Source of information on $\mathrm{CIC}$} \\
\hline Media (radio and television) & 193 & 50.3 \\
\hline Health worker & 122 & 31.8 \\
\hline Friends & 43 & 11.2 \\
\hline Others & 26 & 6.8 \\
\hline \multicolumn{3}{|l|}{ Brand(s) of ClCs known } \\
\hline Cerelac & 157 & 40.9 \\
\hline Motherluck & 5 & 1.3 \\
\hline Yumvita & 3 & 0.8 \\
\hline Two or more of the brands & 219 & 57.0 \\
\hline \multicolumn{3}{|l|}{ Brand of $\mathrm{CIC}$ used for child } \\
\hline Cerelac & 350 & 91.1 \\
\hline Motherluck & 4 & 1.0 \\
\hline Yumvita & 30 & 7.8 \\
\hline \multicolumn{3}{|l|}{ Package of CIC used } \\
\hline Tin $(400 \mathrm{~g})$ & 307 & 79.9 \\
\hline Sachet (50 g) & 77 & 20.1 \\
\hline \multicolumn{3}{|c|}{ Mothers' opinion on CIC as complementary food } \\
\hline $\begin{array}{l}\text { Helps in infants growth } \\
\text { and development }\end{array}$ & 114 & 29.7 \\
\hline $\begin{array}{l}\text { Provides sufficient nutrient } \\
\text { for infants and young children }\end{array}$ & 36 & 9.4 \\
\hline $\begin{array}{l}\text { Infants and young children } \\
\text { prefer it to infant formula }\end{array}$ & 20 & 5.2 \\
\hline Easy to prepare & 16 & 4.2 \\
\hline $\begin{array}{l}\text { It prevents diseases in infants } \\
\text { and young children }\end{array}$ & 8 & 2.1 \\
\hline Two or more of the opinion & 177 & 46.1 \\
\hline Others & 12 & 3.1 \\
\hline \multicolumn{3}{|c|}{ Duration of $\mathrm{ClC}$ use as complementary food } \\
\hline At least 1 month & 18 & 4.7 \\
\hline $2-6$ months & 127 & 33.1 \\
\hline 7-12 months & 142 & 37.0 \\
\hline More than 12 months & 97 & 25.3 \\
\hline
\end{tabular}

moment. In a day, children were served CIC between 1 and 3 times. A little above six in ten children were served two times $(62.0 \%)$ of CIC in a day. Younger children (6-12 months) were served with CIC more frequent than older children (13-23 months); while the majority of children 6-12 months were served three times $(55.9 \%)$ of CIC in the day, the children aged 13-23 months were served two times (73.8\%) of $\mathrm{CIC}$ in the day. The estimated average weight of a usual tablespoon of CIC given to children was $\sim 15.0 \pm 0.5 \mathrm{~g}$ (Table 3). 
Table 3 Daily intake of commercial infant cereal

\begin{tabular}{llll}
\hline Variable & \multicolumn{3}{l}{ Frequency (\%) } \\
\cline { 2 - 4 } Age groups (months) & $6-12$ & $13-23$ & All \\
\hline $\mathrm{n}$ & 136 & 248 & 384 \\
Tablespoons per serving & & & \\
$1-2$ & $110(80.9)$ & $69(27.8)$ & $179(46.6)$ \\
$3-4$ & $26(19.1)$ & $175(70.6)$ & $179(52.3)$ \\
$\quad \geq 5$ & $0(0.0)$ & $4(1.6)$ & $4(1.0)$ \\
Mean tablespoons \pm SD & $2.15 \pm 0.54$ & $2.95 \pm 0.73$ & $2.67 \pm 0.77$ \\
Frequency CIC is served per day & & & \\
$\quad$ Once & $5(3.7)$ & $29(11.7)$ & $34(8.9)$ \\
$\quad$ Two times & $55(40.4)$ & $183(73.8)$ & $238(62.0)$ \\
$\quad$ Three times & $76(55.9)$ & $36(14.5)$ & $112(29.2)$ \\
Weight of tablespoon of CIC (g) & & & Mean \pm SD \\
$\quad \mathrm{n}$ & & & 20 \\
$\quad$ Cerelac & & & $14.6 \pm 3.0$ \\
$\quad$ Yumvita & & & $15.3 \pm 3.4$ \\
Both & & & $15.0 \pm 0.5$ \\
\hline
\end{tabular}

\section{Micronutrient content and intake of commercial infant cereals}

Table 4 presents the micronutrient content per $100 \mathrm{~g}$ of the most preferred brands and flavour, and per tablespoon of CIC consumed by children in this study. The micronutrient content of CIC (as stated by the manufacturer) varied greatly among different brands of CIC. For example, while the iron content of Yumvita was $12 \mathrm{mg}$ per $100 \mathrm{~g}$, the iron content of Cerelac and Motherluc were $7.5 \mathrm{mg}$ per $100 \mathrm{~g}$ and $2.6 \mathrm{mg}$ per $100 \mathrm{~g}$ respectively.

The mean \pm SD of micronutrient intake from CIC were $6.76 \pm 2.67 \mathrm{mg}, 4.79 \pm 1.70 \mathrm{mg}$, $384.12 \pm 139.69 \mathrm{mg}, 266.70 \pm 100.74 \mathrm{mg}$ and
$69.11 \pm 24.65(\mu \mathrm{g})$ for the minerals; Iron, Zinc, Calcium, Phosphorus and Iodine respectively. The vitamin intakes were; vitamin A $(337.17 \pm 119.70 \mu \mathrm{g})$, vitamin C $(42.88 \pm 15.28 \mathrm{mg})$, vitamin B12 $(0.84 \pm 0.31 \mu \mathrm{g})$, folic acid $(34.24 \pm 12.22 \mu \mathrm{g})$ and niacin $(2.70 \pm 1.03 \mathrm{mg})$. Micronutrients from $\mathrm{CIC}$ consumption contributed to at least $70 \%$ of the RNIs for Iron, Zinc, Calcium, Iodine, vitamin $\mathrm{A}$, vitamin $\mathrm{C}$ and vitamin B12 (Table 5).

\section{Discussion}

This study sought to determine the use of CIC as complementary food, the consumption levels among different age groups of IYC, the micronutrient content of commonly used CIC and reasons mothers prefer CIC to enriching local complementary foods. The main findings were that CIC use among mothers was high, younger children 6-12 months were more likely to depend entirely on $\mathrm{CIC}$ as complementary food but not those aged 13-23 months and mothers held various reasons and opinions (including; believing that CIC help in infant growth and development, provides sufficient nutrients for their children and easy to prepare) for depending on CIC as complementary food for their children instead of giving a diversified diet made of locally available and nutritious foods.

The high use of CIC as complementary food among mothers in this study is consistent with the findings of a study in urban Ghana among mothers giving complementary foods [20]. A recent survey of the market revealed a wide range of different $\mathrm{CIC}$ brands on the Ghanaian market [21], probably driven by a high demand. Mothers in this study believed that the use of CIC was good for child growth and development and was enough to meet the nutritional needs of their IYC. This is probably the reason for the high demand of CIC by mothers. With this notion that CIC could meet the

Table 4 Micronutrient content of infant cereals per $100 \mathrm{~g}$ and per tablespoon

\begin{tabular}{|c|c|c|c|c|c|c|}
\hline \multirow{3}{*}{$\begin{array}{l}\text { Micronutrient } \\
\text { Content }\end{array}$} & \multicolumn{6}{|c|}{ Brand of infant cereal } \\
\hline & \multicolumn{2}{|c|}{ Cerelac (wheat) } & \multicolumn{2}{|c|}{ Yumvita (wheat) } & \multicolumn{2}{|c|}{ Motherluc wheat cereal } \\
\hline & Per $100 \mathrm{~g}$ & Per tablespoon & Per $100 \mathrm{~g}$ & Per tablespoon & Per $100 \mathrm{~g}$ & Per tablespoon \\
\hline Iron (mg) & 7.5 & 1.125 & 12 & 1.80 & 2.6 & 0.39 \\
\hline Zinc (mg) & 5.5 & 0.825 & 6 & 0.90 & ns & - \\
\hline Phosphorus (mg) & 320 & 48.0 & 200 & 30.0 & 84 & 12.6 \\
\hline lodine $(\mu g)$ & 80 & 12.0 & ns & - & ns & - \\
\hline Vitamin A ( $\mu \mathrm{g}$ RAE) & 390 & 58.50 & 390 & 58.5 & ns & - \\
\hline Vitamin C (mg) & 50 & 7.50 & 45 & 6.75 & ns & - \\
\hline Vitamin B12 ( $\mu \mathrm{g})$ & 1 & 0.15 & 0.6 & 0.09 & ns & - \\
\hline Folic acid $(\mu \mathrm{g})$ & 40 & 6.00 & 35 & 5.25 & ns & - \\
\hline Niacin (mg) & 3 & 0.45 & 4.5 & 0.675 & ns & - \\
\hline
\end{tabular}

1 tablespoon $=15.0 \mathrm{~g}$

ns not stated 
Table 5 Estimated daily micronutrient intake from commercial infant cereals

\begin{tabular}{|c|c|c|c|c|c|c|c|}
\hline Micronutrient & $n$ & 6-12 months & $\% \mathrm{RNI}$ & 13-23 months & $\%$ RNI & All & $\% \mathrm{RNI}$ \\
\hline \multicolumn{8}{|l|}{ Minerals (mean \pm SD) } \\
\hline Iron (mg) & 384 & $6.44 \pm 2.62$ & 83.61 & $6.93 \pm 2.68$ & 114.43 & $6.76 \pm 2.67$ & 122.89 \\
\hline Zinc (mg) & 380 & $4.56 \pm 1.68$ & 111.12 & $4.92 \pm 1.71$ & 120.03 & $4.79 \pm 1.70$ & 116.84 \\
\hline Calcium (mg) & 384 & $368.48 \pm 134.87$ & 92.12 & $392.70 \pm 141.80$ & 78.54 & $384.12 \pm 139.69$ & 83.35 \\
\hline Phosphorus (mg) & 384 & $256.17 \pm 96.80$ & na & $272.47 \pm 102.58$ & na & $266.70 \pm 100.74$ & na \\
\hline lodine $(\mu \mathrm{g})$ & 350 & $65.40 \pm 24.21$ & 72.67 & $71.22 \pm 24.71$ & 79.13 & $69.11 \pm 24.65$ & 76.79 \\
\hline \multicolumn{8}{|l|}{ Vitamins (mean \pm SD) } \\
\hline Vitamin A ( $\mu \mathrm{g}$ RAE) & 380 & $320.89 \pm 117.55$ & 80.22 & $346.24 \pm 120.17$ & 86.56 & $337.17 \pm 119.70$ & 84.29 \\
\hline Vitamin C (mg) & 380 & $40.84 \pm 14.96$ & 136.14 & $44.02 \pm 15.37$ & 146.73 & $42.88 \pm 15.28$ & 142.94 \\
\hline Vitamin B12 $(\mu \mathrm{g})$ & 380 & $0.80 \pm 0.30$ & 114.15 & $0.86 \pm 0.32$ & 95.35 & $0.84 \pm 0.31$ & 102.08 \\
\hline Folic acid $(\mu \mathrm{g})$ & 380 & $32.61 \pm 11.96$ & 40.77 & $35.14 \pm 12.30$ & 23.43 & $34.24 \pm 12.22$ & 29.63 \\
\hline Niacin mg & 380 & $2.56 \pm 1.01$ & 63.96 & $2.77 \pm 1.03$ & 46.26 & $2.70 \pm 1.03$ & 52.60 \\
\hline
\end{tabular}

na RNI not available for this nutrient

nutritional needs of their children and promote growth, mothers may not see the need to include locally available and nutrient dense complementary foods which would improve dietary diversity and meet nutritional needs. Contrary to our findings, an earlier study reported convenience as a major influence for the use of CIC with health benefits as second.

The majority of mothers used Cerelac (Nestle Ghana limited) as their preferred brand of CIC for complementary feeding. The dominance of Cerelac as a preferred $\mathrm{CIC}$ in present study is consistent with earlier studies in Ghana $[20,21]$. The wide use of this brand could be due to the variety of flavours it presents (maize, wheat, rice, millet, yummy fruits and fruits) and the longer years it has been on the Ghanaian market as well as a strong media marketing. With Cerelac, mothers can easily vary the flavours from time to time to suit child's preference or provide variety, however, the most preferred flavour was wheat flavour. The other available brands did not have as many flavours. For instance, Yumvita (Promasidor Ghana limited) had only two flavours (wheat and maize \& wheat) and Motherluc (Atona foods investments Ghana) was available as only wheat flavour. As mothers change these flavours, it might appear to them as though they are diversifying the diet for their children, but it is the same cereal based foods eaten on different days, usually as child becomes fed up with one flavour. This does not increase the diet diversity of children.

Children were served CIC between one and three times in a day. Similar frequency of infant cereal consumption has been reported among Ghanaian children [20]. Our data further reveals that younger children were fed CIC more frequent than older children. For younger children, high frequency of feeding CIC may mean fewer eating moments to offer other foods from the household.
This makes these children almost entirely dependent on CIC for nutrients apart from breastmilk especially because mothers believe that CIC alone could satisfy the nutritional needs of their children. The lower frequency of feeding CIC among older children may be explained by the introduction and continuing feeding of household food. Further, it may be relatively more expensive to feed older children CIC more frequently because the quantity of intake may increase.

To meet micronutrient requirements of children taking complementary foods, fortified foods have been suggested to be included [26] and data from studies in different developing country settings have emphasized the importance of fortified foods in meeting micronutrient needs. For example, a study in Indonesia found that without inclusion of fortified foods (including infant cereal), it was unlikely for children especially those from low socioeconomic households to have adequate intakes of iron, zinc, niacin and thiamin [27]. Another study in rural Kenya has shown that dietary adequacy of iron, zinc and calcium are unlikely to be met by consumption of only local complementary foods and suggests fortified foods to ensure their adequacy [28]. Results from a study among South African children also show higher intake of iron, zinc, vitamin $\mathrm{A}$, vitamin $\mathrm{C}$, vitamin $\mathrm{B} 6$, vitamin $\mathrm{B} 12$ and niacin from complementary foods including CIC [29]. It is important to note that, CIC in these studies was given with other local complementary foods and therefore diet diversity was likely to be high and CIC added to the micronutrients from other foods consumed. For children to meet adequate intakes especially among the younger children who were less likely to consume other foods, mothers should be encouraged to include locally available and nutrient dense complementary foods to increase the dietary diversity and meet nutritional needs of IYC. 
Cereals contain phytate [30] and polyphenols [31] which reduce the bioavailability of some micronutrients contained in them especially iron and zinc [32, 33]. Overcoming low bioavailability of iron in cereal based complementary foods is perhaps one of the greatest challenges with fortification of infant foods [34].The type of cereal grain used in preparation has little effect on iron bioavailability [35] and dephytinization studies have reported mixed findings [36, 37]. In spite of these, inclusion of enhancers of iron absorption such as ascorbic acid (vitamin $C$ ) has been successful in improving iron bioavailability from infant cereals [32, 38-40]. Estimated iron intake from $\mathrm{CIC}$ in present study is therefore likely to be absorbed as intake levels of vitamin $\mathrm{C}$ from CIC was appreciably high.

The interpretation of the findings in this study need to be made while keeping some limitations in mind. First, we assumed that children ate all portions that were prepared for them at each eating moment, but may not always be the case. There may be leftovers but our estimations of consumption and subsequent calculations did not account for that. If there were many instances of leftover then our estimations of micronutrient intake could be overestimated. We however believe that over time caregivers are able to serve quantities that do not always result in leftovers.

Secondly, we used the nutrient values specified by CIC manufacturers which may not always be entirely correct. Variations between manufacturers' specified values on products and results of independent analyses of product samples have been reported [41, 42]. If the micronutrient contents specified by infant cereal manufacturers were over reported, our estimations of intake could also be overestimated. However, micronutrient content variations between manufacturers' values and analyzed values are not always adverse. For instance, there were no adverse variations in the iodine content of different brands of bouillon cubes in Ghanaian markets between manufacturer values and analyzed values [43]. Moreover, manufacturer nutrient information could be used to build food composition databases [44], suggesting that they could be relied upon for nutrient assessment of foods.

Further studies are warranted to compare micronutrient adequacy of children who consume CIC and those who rely only on family foods and explore the effect of CIC use on recommended infant feeding indicators as present study did not include IYC who receive only family foods.

In spite of these limitations, our results have shed ample light on the use and consumption levels of CIC as complementary food among different age groups of children in Ghana.

\section{Conclusion}

The results of present study show that use of CIC as complementary food was high among mothers with IYC
6-12 months. Mothers believed that CIC was nutritionally adequate for their children and did not see the need to include or enrich other locally available complementary foods. Mothers who offer CIC should be educated on the need to include other locally available and nutrient dense foods in the diets of IYC to ensure nutrient adequacy.

\section{Abbreviations}

CIC: Commercial infant cereal; IYC: Infants and young children; RNI: Recommended nutrient intake; WHO: World Health Organization

\section{Acknowledgements}

The authors are grateful to the mothers and caregivers for their participation in the study.

\section{Funding}

There was no external funding received for this study.

\section{Availability of data and materials}

The data supporting the conclusions of this article are included within the manuscript. The dataset is available from the corresponding author on reasonable request.

\section{Authors' contributions}

Conception and design of study: A-RA, CNE, PA and MA; data collection: CNE, PA and MA; Analysis and interpretation of data: A-RA, ZA, CNE, PA and $M A$; manuscript drafting: $A-R A$ and $Z A$; primary responsibility for the final content: A-RA and ZA. All authors read and approved the final manuscript.

\section{Ethics approval and consent to participate}

Participation in this study was voluntary and participants signed or thumb printed (where mother was illiterate) a statement of an informed consent before she was interviewed. Verbal consent was also obtained from household heads after necessary information was given. Moreover, the permission to carry out this study was sought from the Metropolitan directorate of health. The study protocol was approved by the Scientific Review Committee of the School of Allied Health Sciences, University for Development Studies, Ghana.

\section{Consent for publication}

Not applicable.

\section{Competing interests}

The authors declare that they have no competing interests.

\section{Publisher's Note}

Springer Nature remains neutral with regard to jurisdictional claims in published maps and institutional affiliations.

Received: 28 March 2017 Accepted: 16 August 2017

Published online: 31 August 2017

\section{References}

1. Pan American Health Organization: Guiding principles for complementary feeding of the breastfed child. 2003.

2. Tulchinsky TH. Micronutrient deficiency conditions: global health issues. Public Health Rev. 2010;32(1):243

3. Das JK, Salam RA, Kumar R, Bhutta ZA. Micronutrient fortification of food and its impact on woman and child health: a systematic review. Syst Rev. 2013:2(1):1.

4. Black RE, Victora CG, Walker SP, Bhutta ZA, Christian P, De Onis M, Ezzati M, Grantham-McGregor S, Katz J, Martorell R. Maternal and child undernutrition and overweight in low-income and middle-income countries. Lancet. 2013; 382(9890):427-51

5. Kramer M, Kakuma R. Optimal duration of exclusive breastfeeding (review). Cochrane Database Syst Rev. 2002;1:11-2.

6. WHO, UNICEF, USAID, AED, UCDAVIS, IFPRI. Indicators for assessing infant and young child feeding practices: part 1: definitions: conclusions of a 
consensus meeting held 6-8 November 2007 in Washington DC, USA. Geneva: WHO; 2008.

7. Plessow R, Arora NK, Brunner B, Wieser S. Cost-effectiveness of price subsidies on fortified packaged infant cereals in reducing iron deficiency anemia in 6-23month-old-children in urban India. PLoS One. 2016;11(4):e0152800.

8. Dewey KG, Vitta BS. Strategies for ensuring adequate nutrient intake for infants and young children during the period of complementary feeding. Washington: Alive \& Thrive; 2013.

9. World Health Organization: Global strategy for infant and young child feeding. 2003.

10. Lind T, Lönnerdal B, Persson L-Å, Stenlund H, Tennefors C, Hernell O. Effects of weaning cereals with different phytate contents on hemoglobin, iron stores, and serum zinc: a randomized intervention in infants from 6 to 12 mo of age. Am J Clin Nutr. 2003;78(1):168-75.

11. Dewey KG. The challenge of meeting nutrient needs of infants and young children during the period of complementary feeding: an evolutionary perspective. J Nutr. 2013;143(12):2050-4.

12. Smuts CM, Lombard CJ, Benadé AS, Dhansay MA, Berger J, de Romaña GL, Untoro J, Karyadi E, Erhardt J, Gross R. Efficacy of a foodlet-based multiple micronutrient supplement for preventing growth faltering, anemia, and micronutrient deficiency of infants: the four country IRIS trial pooled data analysis. J Nutr. 2005;135(3):631S-8S.

13. WHO U, USAID, AED, UCDAVIS, IFPRI. Indicators for assessing infant and young child feeding practices, part 2: measurement. Geneva: WHO; 2010.

14. Kennedy GL, Pedro MR, Seghieri C, Nantel G, Brouwer I. Dietary diversity score is a useful indicator of micronutrient intake in non-breast-feeding Filipino children. J Nutr. 2007;137(2):472-7.

15. Moursi MM, Arimond M, Dewey KG, Trèche S, Ruel MT, Delpeuch F. Dietary diversity is a good predictor of the micronutrient density of the diet of 6-to 23-month-old children in Madagascar. J Nutr. 2008;138(12):2448-53.

16. Ayivor J, Debrah S, Forson A, Nuviadenu C, Buah Kwofie A, Denutsui D. Trace elements in some imported commercial infant cereal formulas on the Ghanaian market by INAA. Der Pharma Chemica. 2011;3(5):94-100.

17. Davidsson L, Kastenmayer P, Szajewska H, Hurrell RF, Barclay D. Iron bioavailability in infants from an infant cereal fortified with ferric pyrophosphate or ferrous fumarate. Am J Clin Nutr. 2000;71(6):1597-602.

18. Lutter CK. Macrolevel approaches to improve the availability of complementary foods. Food Nutr Bull. 2003;24(1):83-103.

19. Gibbs M, Bailey KB, Lander RD, Fahmida U, Perlas L, Hess SY, Loechl CU, Winichagoon P, Gibson RS. The adequacy of micronutrient concentrations in manufactured complementary foods from low-income countries. J Food Compos Anal. 2011;24(3):418-26.

20. Pelto GH, Armar-Klemesu M. Balancing nurturance, cost and time: complementary feeding in Accra, Ghana. Matern Child Nutr. 2011;7(s3):66-81.

21. Masters WA, Kuwornu J, Sarpong D: Improving child nutrition through quality certification of infant foods: scoping study from a randomized trial in Ghana. 2011.

22. Ghana Statistical Service. 2010 population and housing census summary report of final results. Accra: Ghana Statistical Service; 2012.

23. Ghana Statistical Service. 2010 population and housing census Distric analytical report tamale metropolis. Accra: Ghana Statistical Service; 2014.

24. Institute of Medicine. Dietary reference intakes: the essential guide to nutrient requirements. Washington, DC: The National Academies Press; 2006.

25. Joint FAO WHO: Vitamin and mineral requirements in human nutrition. 2005.

26. WHO/UNICEF. Complementary feeding of young children in developing countries: a review of current scientific knowledge. Geneva: Who; 1998. p. 230.

27. Fahmida U, Santika O. Development of complementary feeding recommendations for 12-23-month-old children from low and middle socioeconomic status in west java, Indonesia: contribution of fortified foods towards meeting the nutrient requirement. Br J Nutr. 2016;116(Suppl 1):S8-s15.

28. Ferguson E, Chege P, Kimiywe J, Wiesmann D, Hotz C. Zinc, iron and calcium are major limiting nutrients in the complementary diets of rural Kenyan children. Matern Child Nutr. 2015;11(Suppl Suppl 3):6-20.

29. Faber M. Complementary foods consumed by 6-12-month-old rural infants in South Africa are inadequate in micronutrients. Public Health Nutr. 2005; 8(04):373-81.

30. Reddy N, Sathe S, Salunkhe D. Phytates in legumes and cereals. Adv Food Res. 1982;28:1-92.

31. Lachman J, Hosnedl V, Pivec V, Orsák M. Polyphenols in cereals and their positive and negative role in human and animal nutrition. In: Cereals for human health and preventive nutrition, Brno. Czech Republic: Mendelova Zemedelska a Lesnicka Univerzita; 1998.
32. Hallberg L, Brune M, Rossander L. Iron absorption in man: ascorbic acid and dose-dependent inhibition by phytate. Am J Clin Nutr. 1989;49(1):140-4.

33. Gibson RS, Bailey KB, Gibbs M, Ferguson EL. A review of phytate, iron, zinc, and calcium concentrations in plant-based complementary foods used in low-income countries and implications for bioavailability. Food Nutr Bull. 2010;31(2_suppl2):S134-46.

34. Hurrell RF. Fortification: overcoming technical and practical barriers. J Nutr. 2002;132(4):8065-12S.

35. Cook JD, Reddy M, Burri J, Juillerat MA, Hurrell RF. The influence of different cereal grains on iron absorption from infant cereal foods. Am J Clin Nutr. 1997;65(4):964-9.

36. Davidsson L, Galan P, Cherouvrier F, Kastenmayer P, Juillerat M-A, Hercberg $S$, Hurrell RF. Bioavailability in infants of iron from infant cereals: effect of dephytinization. Am J Clin Nutr. 1997;65(4):916-20.

37. Hurrell RF, Reddy MB, Juillerat M-A, Cook JD. Degradation of phytic acid in cereal porridges improves iron absorption by human subjects. Am J Clin Nutr. 2003;77(5):1213-9.

38. Davidsson L. Approaches to improve iron bioavailability from complementary foods. J Nutr. 2003;133(5):1560S-2S.

39. Fairweather-Tait S, Fox T, Wharf SG, Eagles $J$. The bioavailability of iron in different weaning foods and the enhancing effect of a fruit drink containing ascorbic acid. Pediatr Res. 1995:37(4):389-94.

40. Derman D, Bothwell T, MacPhail A, Torrance J, Bezwoda W, Charlton R, Mayet $F$. Importance of ascorbic acid in the absorption of iron from infant foods. Eur J Haematol. 1981;25(3):193-201.

41. Lobanco CM, Vedovato GM, Cano CB, Bastos DHM. Reliability of food labels from products marketed in the city of Sao Paulo, southeastern Brazil. Rev Saude Publica. 2009:43(3):499-505.

42. Fitzpatrick L, Arcand J, L'Abbe M, Deng M, Duhaney T, Campbell N. Accuracy of Canadian food labels for sodium content of food. Nutr. 2014; 6(8):3326-35.

43. Abizari A-R, Dold S, Kupka R, Zimmermann MB. More than two-thirds of dietary iodine in children in northern Ghana is obtained from bouillon cubes containing iodized salt. Public health Nutr. 2017;20(6):1107-13.

44. Schakel SF, Buzzard IM, Gebhardt SE. Procedures for estimating nutrient values for food composition databases. J Food Compos Anal. 1997;10(2): $102-14$

\section{Submit your next manuscript to BioMed Central and we will help you at every step:}

- We accept pre-submission inquiries

- Our selector tool helps you to find the most relevant journal

- We provide round the clock customer support

- Convenient online submission

- Thorough peer review

- Inclusion in PubMed and all major indexing services

- Maximum visibility for your research

Submit your manuscript at www.biomedcentral.com/submit
) Biomed Central 